\title{
TITLE:
}

\section{On the foundations of the minimal model program}

$\operatorname{AUTHOR}(\mathrm{S})$ :

藤野, 修

CITATION:

藤野, 修. On the foundations of the minimal model program. 代数幾何 学シンポジウム記録 2015, 2015: 148-164

ISSUE DATE:

2015

URL:

http://hdl.handle.net/2433/218259

RIGHT: 


\title{
On the foundations of the minimal model program
}

\author{
極小モデル理論の基礎について \\ 京都大学大学院理学研究科数学教室 \\ 藤野 修* \\ Osamu Fujino \\ Department of Mathematics, Graduate School of Science, \\ Kyoto University \\ 平成 27 年 11 月 5 日
}

\section{概 要}

極小モデル理論の基礎について私の個人的な考えを中心に論じ たい。今までの極小モデル理論は川又-Viehweg 消滅定理に大きく 依存していたが、新しいコホモロジーの消滅定理のパッケージを確 立し、極小モデル理論の基礎の新たな枠組みを提供する。

\section{目次}

1 はじめに 2

2 極小モデル理論の歴史 2

3 準備と背景 4

4 新しいコホモロジーの消滅定理のパッケージ 6

*\% 606-8502 京都市左京区北白川追分町, e-mail: fujino@math.kyoto-u.ac.jp 
5 動機付け $\quad 8$

6 文献案内と宣伝 9

7 古典的な極小モデル理論との比較 11

8 消滅定理についての私の個人的な考え 13

8.1 川又-Viehweg 消滅定理について . . . . . . . . . . 13

8.2 川又-Viehweg 消滅定理と Nadel 消滅定理について . . . . 15

8.3 今後の課題 . . . . . . . . . . . . . . . . 16

9 おしまい 16

10 謝辞 16

\section{1 はじめに}

これは城崎シンポジウムの報告集の原稿なので、城崎での講演内容を おとなしく簡潔にまとめて書いておけばよいのであろう。しかし、極小 モデル理論の最先端の結果のいくつかを厳密な形でここに書き記しても、 大半の人は読まないであろう。論文やプレプリントのコピー\&ペースト のような報告書を書くことは私のポリシーにもあわない。なので、この報 告書では定義や定理は必要最小限にし、私の個人的な考えを中心に書き たい。この報告書に書いてあることは私の個人的な考えなので、当然の ことながら、極小モデル理論の既存の価值観とかなり乘離している部分 もある。そもそも、極小モデル理論の既存の枠組みでは飽き足らなかった ので新しい枠組みを模索したというのが私の最近の研究成果である。し たがって、普通の人の考えと合わない部分があっても当然であろう。

\section{2 極小モデル理論の歴史}

1980 年頃に森によって始められた極小モデル理論 (森理論とも呼ばれ る) は、1980年代から 90 年代半ばにかけて大発展した。これが極小モデ ル理論の第一次黄金時代だと思う。私より上の世代の研究者は、直接的、 間接的にこの大発展を目にしていたと思う。この最初の黄金時代には、3 次元代数多様体の極小モデル理論に関するほぼ全ての予想が解決された。 
この時期に導入された新しいアイデアやテクニックは、その後の代数幾 何学に大きな影響を与えたと思う。ここからは私の個人的な意見である。 この極小モデル理論の最初の黄金期には、高次元代数多様体とは主に 3 次 元代数多様体を指していたと思われる。今現在の私の感覚では、3次元は 高次元ではなく低次元である。私の印象では、森による 3 次元の極小モ デル理論は、ある意味一番内容豊かな 3 次元代数多様体の世界をほとん ぞ素手で調べ尽くした、である。森による 3 次元収縮射の分類、3 次元末 端特異点の分類、3 次元フリッピング収縮の解析などなどは、あまり大掛 かりな道具は使わず、素手で難敵を倒した感じである。偉そうに森の仕 事について論じているが、私は師匠 (森先生は私の大学院時代の指導教官 である)の論文は読まない！と若かりし日に軽く決意したので、私は森の 論文はほとんど読んでいない。なので、上の記述は私のたんなる思い込 みかもしれない。この第一次黄金時代のまとめとして書かれたのが、現 在の極小モデル理論のバイブルの一つ $[\mathrm{KM}]$ である。この本の原稿を読む ということが修士課程 1 年の私に課せられた使命であった。修業時代に $[\mathrm{KM}]$ の原稿を読ませていただけたのは非常に幸運であった。

次の黄金期がいつからいつまでなのかはよく分からないが、2006 年に プレプリントが出た Birkar-Cascini-Hacon-McKernan の大結果 [BCHM] が極小モデル理論の発展の頂点の一つであろう。 80 年代後半に導入され た Nadel 消滅定理や Ohsawa-Takegoshi 拡張定理の応用など、90 年代に は複素解析的な手法が高次元代数多様体論に大きな影響を与えた。解析 的な手法の多くは直ちに代数幾何学的手法に翻訳され、たくさんの問題 に適用されていった。一方、第一次黄金時代から活躍していた Shokurov は、極小モデル理論の一般次元化のためにたくさんのアイデアを出して いた。ただし、Shokurov の論文は非常に難解なことで有名であり、彼の アイデアを理解することはなかなか難しかったのである。この Shokurov による高次元化への取り組みと代数的乗数イデアル層や Nadel 消滅定理 の理論の融合が、Birkar-Cascini-Hacon-MK Kernanの大結果につながつ たのである。その後も同じ方向性での発展は続いており、極小モデル理 論の大予想のいくつかは一般次元で完全に解決されている。第二次黄金 時代はまだ続いていると言ってよいであろう。私も一応この第二次黄金 時代の大発展にささやかながら貢献したと思っている。で、ここからは 私の印象である。Hacon とその共同研究者達や、Birkar とその共同研究 者達は、様々な予想を一般次元で次々と解決していっている。新しい数 学を生み出すというよりは、既存のテクニックや最新の結果などを巧妙 
に使いこなし、一般的な設定で豪快に未解決問題を解決していっている のである。藤野權業ペアの仕事のいくつかも同じ路線であろう。ここで 少し不安になるのである。もしかして代数多様体論もトポロジーと同じ なのか …と。3 次元や 4 次元のトポロジーは非常に内容が豊かである。 一方、5次元以上のトポロジーは殺風景な印象を受ける。もちろんこれは 私の勝手な感想である。極小モデル理論はどうであろうか ? 2 次元から 3 次元への一般化によって代数多様体論は確実に進歩し、3 次元代数多様体 論が実り多き分野であることは今や明らかである。4次元以上の世界はど うであろうか?やはり代数多様体論も低次元 (3 次元以下) が面白く、高次 元 (4 次元以上) は思ったほど内容が豊かではないのだろうか ?いずれに せよ、私の専門は主に高次元代数多様体論で、低次元 (3 次元以下の) 代 数多様体論ではないのである。私はそれほど 3 次元代数多様体論は詳し くないのである。かなり困った状態なのである。

2006 年の秋に Birkar-Cascini-Hacon-McKernan のプレプリントを見た 後、2007 年あたりから始めた話が今回の城崎の講演の内容であった。み なと同じ方向を向いて研究をしていても面白くないので、独自路線を選 んだのである。目標は単純で、極小モデル理論の基礎の一新である。私 の仕事は極小モデル理論の発展の歴史の中で見ると、現在のところ異端 である。もちろん、近い将来、私のつくつた枠組みが極小モデル理論の スタンダードになると信じているし、おそらくそうなるであろう。古典 的な極小モデル理論の基礎を刷新し、極小モデル理論を次のステージに 進めるための第一段階はほぼ完成したと思っている。

残念ながら、私のような方法で極小モデル理論の基礎を書き直しても、 実り多き土地にはたどり着きそうにない。広大な土地を切り開いたが、砂 漠に高速道路を建設している感じである。どんどん土地は切り開かれてい くのだが、かなり殺風景である…。この報告書を読んだ人のなかから、 特別な次元でエキゾチックな構造を見つけたり、砂漠の中にオアシスを 見つけてくれる人が出てくれることを願う。

\section{3 準備と背景}

まず始めに、川又対数的末端対 (KLT)、対数的標準対 (LC)、半対数的 標準対 (SLC) について少し注意しておこう。もちろん、KLT、LC、SLC の順番に特異点のクラスは広くなっている。極小モデル理論の専門家以 外は KLT やLC などの用語に困惑することが多いと思う。ここでは厳密 
な定義はせずに、私のイメージを説明したい。1次元の場合は、

・ 非特異曲線が KLT

・点付き非特異曲線が LC

・結節点を許した (必ずしも既約とは限らない) 点付き曲線が SLC

というイメージである。2 次元の場合は

・高々商特異点を許した曲面が KLT

・さらに楕円型特異点も許した曲面は LC

- Whitney の傘 $\left(x^{2}-z y^{2}=0 \subset \mathbb{C}^{3}\right)$ のような曲面や (既約とは限らな い) 正規交叉曲面は SLC

である。上の説明はかなり雑であり、厳密な定義ではない。あくまで私の イメージを述べただけである。厳密には特異点解消と食い違い係数 (discrepancy) を使って定義される。非特異な代数多様体や素朴な意味での極 小モデルや標準モデルを考えるだけなら KLT の世界で十分である。ただ し、証明の都合上、LC や SLC まで広げて考える方が自然な場合も多い。 非コンパクトな代数多様体を扱ったり、次元による帰納的な構造を調べ るためには、KLTより LCの方が自然な枠組みだと思われている。 SLC はもともとモジュライ空間のコンパクト化の問題から出てきた特異点の クラスであり、安定曲線 (stable curve) の高次元対応物の定義に不可欠で ある。また、SLC はアバンダンス予想の次元による帰納法の際などには 避けて通れない対象のようにも思える。

いずれにせよ、今までの極小モデル理論は、基本的に KLTについて理 論が整備されていた。川又-Viehweg 消滅定理がもつとも威力を発揮する 特異点のクラスが KLT なので、川又-Viehweg 消滅定理を主な道具とし て採用していた従来の極小モデル理論の枠組みでは KLT が中心的な役割 を果たしていたのである。私の考えは単純で、

川又-Viehweg 消滅定理より強力な消滅定理のパッケージを確立し、 極小モデル理論の枠組みを LCまで広げたい。

であった。このアイデアは想定していた以上に上手く実現できた。また、 SLC に対しても極小モデル理論の基本定理たちが成り立つことが証明で 
きた。これは専門家にとっても想定外の結果だったと思われる。証明し た私自身も想定していなかった結果である。上に述べたように SLC はモ ジュライ空間のコンパクト化の問題から導入された特異点のクラスであ り、非正規な多様体や可約な多様体を含むかなり広い特異点のクラスで ある。このようなクラスに対しても錐定理や固定点自由化定理のような 極小モデル理論の基本定理が成り立つことは驚きであろう。

一般的な理解は以下の通りであった。KLTは有理特異点であり、CohenMacaulayである。しかし、LCは一般には有理特異点ではない。したがつ て、3 次元以上の LC 特異点は必ずしも Cohen-Macaulay でない。この事 実は微妙に問題を難しくする。また、LCに対して素朴に川又-Viehweg 消滅定理を適用することはできない。なので、LCに対しては、様々な証 明の際に技術的な困難が増えると思われていた。さらに、SLC は必ずし も正規でないし、可約な場合もある。そもそも可約な多様体を扱うこと は心理的な負担がかなり大きいと思う。このように、LC P SLCを扱う ことは難しいという先入観が世の中に蔓延していたように思う。そこで、 強力なコホモロジーの消滅定理の新しいパッケージを確立して問題を一 網打尽にしてやろう！と若かりし日の私は野心を抱いたのである。天の 邪鬼で流行に乗るのが嫌いな私にとっては最適の問題だったのである。

\section{4 新しいコホモロジーの消滅定理のパッケージ}

この章ではまじめに新しいコホモロジーの消滅定理のパッケージにつ いて述べておこう。すべて複素数体上で考えることにし、すべて代数的 な設定で考える。証明は混合ホッジ構造の理論を使うので、一般の複素 解析空間ではなく、代数的な枠組みで論じる必要があるのである。

4.1 (設定) $M$ を非特異代数多様体とし、 $X$ を $M$ 上の単純正規交叉因子 とする。 $B$ を $M$ 上の $\mathbb{R}$-因子で $\operatorname{Supp} B$ が単純正規交叉因子になるものと する。 $B$ と $X$ は共通成分を持たず、 $\operatorname{Supp}(B+X)$ は単純正規交叉因子と 仮定する。このとき、 $D=\left.B\right|_{X}$ とおいて、 $(X, D)$ を「大域的に埋め込ま れた単純正規交叉対 (globally embedded simple normal crossing pair)」と 呼ぶことにする。代数多様体 $Y$ とその上の因子 $\Delta$ の対 $(Y, \Delta)$ が単純正規 交叉対 (simple normal crossing pair) とは、ザリスキ位相で局所的に「大 域的に埋め込まれた単純正規交叉対」と同型になることとする。 
$(X, D)$ を単純正規交叉対とし、 $D$ の係数は 0 以上 1 以下とする。 $\nu$ : $X^{\nu} \rightarrow X$ は $X$ の正規化とする。このとき、因子 $\Theta$ を

$$
K_{X^{\nu}}+\Theta=\nu^{*}\left(K_{X}+D\right)
$$

で定義する。今の場合、 $\Theta$ は $D$ のでの引き戻しと $X$ の特異点集合の逆 像の合併である。 $X^{\nu}$ は非特異になり、Supp $\Theta$ は $X^{\nu}$ 上の単純正規交叉因 子で $\Theta$ の係数は 0 以上 1 以下であることもすぐに分かる。

ここで $W$ を $X$ の閉部分多様体とする。 $\left(X^{\nu}, \Theta\right)$ の対数的標準中心 $(\log$ canonical center $C$ があって $W=\nu(C)$ となるか、 $W$ が $X$ の既約成分の とき、 $W$ は $(X, D)$ の階層 (stratum) であるという。 $\left(X^{\nu}, \Theta\right)$ の対数的標 準中心とは、今の設定では、 $\Theta$ の係数が 1 の部分の既約成分の有限個の 交わりの既約成分のことである。

これで準備は整った。

定理 $4.2(Y, \Delta)$ は単純正規交叉対とし、 $\Delta$ の係数は 0 以上 1 以下とする。 $f: Y \rightarrow X$ は固有射とする。 $L$ は $Y$ 上のカルティエ因子で $L-\left(K_{Y}+\Delta\right)$ は $f$-半豊富とする。このとき、以下の主張が成り立つ。

(i) 任意の $q$ に対し、 $R^{q} f_{*} \mathcal{O}_{Y}(L)$ の随伴素イデアル (associated prime) は $(Y, \Delta)$ のある階層の $f$ での像の生成点である。

(ii) さらに $\pi: X \rightarrow V$ を射影射とし、 $X$ 上の $\pi$-豊富な $\mathbb{R}$-因子 $H$ が存 在して $L-\left(K_{Y}+\Delta\right) \sim_{\mathbb{R}, \pi} f^{*} H$ と書けたとする。このとき、

$$
R^{p} \pi_{*} R^{q} f_{*} \mathcal{O}_{Y}(L)=0
$$

がすべての $p>0$ と $q \geq 0$ に対して成立する。

定理 4.3 定理 4.2 の設定で、 $(Y, \Delta)$ は「大域的に埋め込まれた単純正規交 叉対」または $Y$ は擬射影的と仮定する。このとき、Hが $V$ 上 $f:(Y, \Delta) \rightarrow$ $X$ に関して数值的非負かつ対数的巨大という条件で定理 4.2 の (ii) の消滅 定理は成立する。ただし、 $H$ が $V$ 上 $f:(Y, \Delta) \rightarrow X$ に関して数值的非負 かつ対数的巨大とは、 $H$ は $V$ 上数值的に非負で、 $(Y, \Delta)$ のすべての階層 $W$ に対して $\left.H\right|_{f(W)}$ が $V$ 上相対的に巨大ということである。 $H$ が $V$ 上相 対的に豊富なら、これらの条件は明らかに満たされる。 
このように定式化しておくと、定理 4.2 と定理 4.3 は川又-Viehweg 消 滅定理、(代数的なバージョンの) Nadel 消滅定理、Kollár の捻れ不在定 理や消滅定理などを特殊な場合として含んでいる。実際に定理 4.2 や定理 4.3 を使う場合は、このままでは使い難いので、適当に特殊化して使いや すい形にして使うことが多い。定理 4.2 や定理 4.3 の特殊化として得られ る消滅定理のいくつかは、川又-Viehweg 消滅定理や (代数的なバージョ ンの)Nadel 消滅定理より遥かに強力で使い勝手がよい。今のところそれ ら有益な特殊化に特別な名前はついていないと思う。

ここでは定理 4.2 と定理 4.3 の証明については詳しくは述べない。証明 はコンパクト台コホモロジーの混合ホッジ構造の理論を使う。コンパク ト台コホモロジーの混合ホッジ構造をつかえばよいと気付いた点が私の 最大の貢献だと思う。それさえ分かれば、実際の証明は 80 年代や 90 年代 に書かれた消滅定理の証明を上手く書き直していくだけである。

定理 4.2 と定理 4.3 (とそれらの特殊化) を基礎に据えて極小モデル理論 の基礎を書き直していったのが私のここ数年の一連の仕事である。従来の 極小モデル理論の基礎では、上記定理の特殊化の一つである川又-Viehweg 消滅定理だけしか使っていなかったのである。現在は強力なコホモロジー の消滅定理のパッケージが使えるようになったので、理論の適用範囲は 劇的に広がったし、各種定理の証明もかなり簡略化されたのである。理 想的な発展の形だと思う。私の仕事は世間ではあまり理解されていない ようなので強調して書いておく。大袈梁に書くと、

KLT に対して整備されていた従来の極小モデル理論の基礎の上に新 たな理論を積み上げるのではなく、最初から新しい枠組みで極小モ デル理論の基礎理論を全部書き直したのである。

である。

\section{5 動機付け}

少しだけ数学の話をしよう。 $X$ を非特異射影多様体とし、 $D$ を数值的 非負なカルティエ因子とする。 $D-K_{X}$ が豊富のとき、十分大きな $m$ に 対して線形系 $|m D|$ が固定点をもたないという事実は、固定点自由化定理 よりしたがう。

2003 年か 2004年か覚えていないが、プリンストンに滞在中の私に Julien 
Keller(だったと思う) が次のような質問をしてきた。上の主張を特異点解 消定理などを使わずに簡単に示せないのか？と和もちろん彼の頭には Nadel 消滅定理があったのだと思う。私は極小モデル理論にドップリと浸 かっていたので、それまでこのような素朴な疑問は持ったことがなかっ たように思う。特異点解消定理と川又-Viehweg 消滅定理を駆使した証明 方法 (それはX 論法と呼ばれる) は、解析的手法を専門にする人にはなん だか分かりにくい議論だったようである。おそらく数年後のことだと思 うが、高木俊輔さんにも同様の質問をされた記憶がある。川又-Viehweg 消滅定理ではなく、(特異点解消定理は使わずに) Nadel 消滅定理で固定点 自由化定理は証明できないのか？と。これらの質問はずっと私の頭の中 でひっかかっていたのである。

定理 4.2 の特殊化としていくつか使い易い定理を準備しておく。その中 の一つは (代数的なバージョンの) Nadel 消滅定理の自然な一般化である。 このように十分な準備をしておくと、固定点自由化定理は簡単に証明で きる。この私の証明に対する MathSciNet上の Pukhlikovによるレビュー には、The proof is surprisingly short and easy. と書いてある。さらに、 私の証明方法は LC に対して適用可能である。詳しくは私の論文

- Non-vanishing theorem for log canonical pairs, J. Algebraic Geom. 20 (2011), no. 4, 771-783.

を見ていただきたい。これが Keller と高木の質問に対する私の解答であ る。彼らの質問が極小モデル理論の新しい枠組みを作る動機付けになっ たことは間違いない。

\section{6 文献案内と宣伝}

極小モデル理論のバイブルである $[\mathrm{KMM}]$ や $[\mathrm{KM}]$ では、川又-Viehweg 消滅定理を用いて錐定理や固定点自由化定理を KLTの世界で証明してい る。実際はKLTより少し広い世界で理論を展開しているが、いわゆる対 数的末端対 (LT) の世界にとどまっている。川又-Viehweg 消滅定理の適 用限界のせいで、LCではなく LT の世界で理論を展開しなくてはいけな かったのであろう。私の論文

1英会話能力の低い私と (フランス語訛？の) 彼との日常会話は全く噛み合っていな かったが、数学に関する会話はギリギリ成立していたと思う。 
- Fundamental theorems for the log minimal model program, Publ.

Res. Inst. Math. Sci. 47 (2011), no. 3, 727-789.

では、この問題は完全に解決されている。川又-Viehweg 消滅定理より真 に強力な消滅定理のパッケージを用意することにより、LCの世界で錐定 理や固定点自由化定理などを証明している。実際には LC を含むさらに広 い世界で極小モデル理論の基本定理を証明している。ただし、4章で述べ たほどには消滅定理は一般的には論じていない。消滅定理の部分は必要 最小限にし、先を急いだ感じになっている。この論文では、消滅定理の 証明を短くするために極小モデル理論の大結果である $[\mathrm{BCHM}]$ の結果を 援用している。なので、厳密に言うと、この論文は $[\mathrm{KMM}]$ や $[\mathrm{KM}]$ の結 果から完全に独立にはなっていない。もちろん消滅定理の部分は極小モ デル理論とは完全に独立に証明することが可能である。消滅定理の部分 の証明を私の他の論文の議論で置き換えればいいだけである。この論文 で展開した枠組みの応用として、論文

- Minimal model theory for log surfaces, Publ. Res. Inst. Math. Sci. 48 (2012), no. 2, 339-371.

がある。特異な曲面の極小モデル理論を論じている。従来考えられてい たより遥かに広い対象に対して極小モデル理論が適用可能になっている。 今までの曲面論とは少しおもむきが異なるはずである。私のお気に入り の論文の一つである。その後、この曲面論は、田中公さんの修士論文で基 礎体が正標数の場合にも一般化された。そこでは消滅定理ではなく、フ ロベニウス写像が活躍している。論文

- Fundamental theorems for semi log canonical pairs, Algebr. Geom. 1 (2014), no. 2, 194-228.

では錐定理や固定点自由化定理など極小モデル理論の基本定理をSLCに 対して証明している。これらは想定外の結果であろう。擬射影的 SLCに 擬対数的スキーム (quasi-log scheme) の構造が自然に入ることを示した のがこの論文の主結果である。その帰結として、極小モデル理論の基本 定理がSLCに対して成り立つことがわかる。なぜなら、すでに我々は擬 対数的スキームに対して十分な一般論を展開していたからである。ただ し、擬対数的構造は元々は Ambroによって 2000 年代前半に導入された ものである。擬対数的スキームについては 
- Foundation of the minimal model program, preprint. 2014/4/16 version 0.01

に詳しく述べてある。これは現在投稿中の本の原稿である。この原稿は 2014 年に書かれたものであるが、元々は 2007 年に書かれた未出版のプレ プリント 2 編からなる。 2007 年に書かれたプレプリントたちは、その当 時、 $[\mathrm{BCHM}]$ の解読作業や勉強会に忙しかった極小モデル理論の研究者 たちには全く見向きもされなかったようである。その後、紆余曲折を経 て、本の原稿としてまとめられている。この原稿は教科書ではなく、解 説部分を充実させた論文である。

\section{7 古典的な極小モデル理論との比較}

$[\mathrm{KM}]$ を使って古典的な極小モデル理論と新しい枠組みの比較をしてみ よう。

7.1 一つ目は LC についてである。 $[\mathrm{KM}]$ の日本語版の 73 ページには以 下のような記述がある。

(5) ログ標準的 ${ }^{2}$ : このクラスは食い違い係数がまだ意味をも つような最大のクラスである。残念ながら、コホモロジーの 視点からは複雑な場合を多く含んでいる。従って使いづらい クラスでもある。

この記述は $[\mathrm{KM}]$ が書かれた 90 年代後半の極小モデル理論の専門家に とっては自然な主張である。しかし、この記述は現在の新しい枠組みで は全く正しくない。 $[\mathrm{KM}]$ の書かれた当時は、廣中の特異点解消定理と川 又-Viehweg 消滅定理しか使わないという暗黙の大前提があったが、現在 はもつと強力なコホモロジーの消滅定理のパッケージが確立されているの である。4 章で述べた話である。なので、ある意味 KLTより LCの方がコ ホモロジーの視点からは自然で扱い易い対象になっている。川又-Viehweg 消滅定理しか使わないという大前提が変わってしまったからである。

7.2 二つ目は消滅定理の証明に関する話である。[KM] の日本語版の 91 ページには以下のような記述がある。

\footnotetext{
${ }^{2}$ ログ標準的は私の用語では対数的標準のことである。
} 
注意 2.66 Serre 双対により、 $H^{i}\left(X, L^{-1}\right)$ の消滅定理は $H^{n-i}\left(X, \omega_{X} \otimes L\right)$ の消滅定理に同值であるが、定理 2.64 の証 明の途中でこの 2 つの主張は異なる挙動を示す。段階 1-3 は $H^{i}\left(X, L^{-1}\right)$ の消滅定理を扱っている。同じ段階で双対版の消 滅定理を扱うのは可能だが、 $\omega_{Z}$ と $\omega_{X}$ の注意深い比較が必要 で、より難しくなる。

最後の段階で $H^{n-i}\left(X, \omega_{X} \otimes L\right)$ の消滅定理を扱ったが、それ はここで $H^{i}\left(X, L^{-1}\right)$ を报うとより難しくなるからである。

上に引用した部分だけを読んでも意味はよく分からないと思うが、消滅 定理の証明のこの辺の議論にこだわっていろいろ考えると、コンパクト台 コホモロジーの混合ホッジ構造を使うことが自然に思えてきたような記憶 がある。 $X$ を非特異射影多様体とし、 $D$ を $X$ 上の単純正規交叉因子とする。 このとき、 $\mathcal{O}_{X}\left(K_{X}+D\right)$ を $\Lambda^{\operatorname{dim} X} \Omega_{X}^{1}(\log D)$ ではなく、 $\mathcal{O}_{X}\left(K_{X}+D\right) \simeq$ $\mathcal{H} o m\left(\Omega_{X}^{0}(\log D) \otimes \mathcal{O}_{X}(-D), \omega_{X}\right)$ と見る方がホッジ理論をつかった消滅 定理の証明という観点からは自然に思えてくるのである。

7.3 最後は SLC についてである。 $[\mathrm{KM}]$ の日本語版の 260 ページには以 下のような記述がある。

注意 7.5 多くの応用では $f^{-1}(c)$ の正規でない特異点を理 解することも重要である。この問題意識により lc 対 ${ }^{3} の$ 概念の 非正規版が導入された。これらのいわゆる半ログ標準的(略し て、slc) 対 4 の理論は lc 対の場合とあまり違わないが、そ机で もいくつかの基本的な問題を解決しなければならない。詳細 は $\left[\mathrm{KSB} 88, \mathrm{~K}^{+} 92\right]$ に㗒る。

この記述は非常に乱暴である。 $[\mathrm{KM}]$ の書かれた当時は LCに対しても十 分な一般論が建設されていなかった。そのような状況にも関わらず、SLC の理論は LC の場合とあまり違わないと主張しているのである。今現在 は、大方の予想に反して、SLC の世界に対しても強力なコホモロジーの 消滅定理のパッケージを展開することが可能になっている。SLC の場合 はLCの場合に比べると遥かに面倒であるが、 4 章で述べたパッケージを 上手く適用することができるのである。その帰結として、錐定理や固定 点自由化定理など極小モデル理論の基本定理がすべて SLCで成立するこ とが分かっている。

\footnotetext{
ここの報告書では LC と大文字で書いているが、 lc と小文字で書く場合も多い。

4半ログ標準的は私の用語では半対数的標準のこと。SLC のことである。
} 


\section{8 消滅定理についての私の個人的な考え}

消滅定理について私の個人的な考元を書いておきたい。以下の文章を 書くためにオリジナルの文献で自分自身の理解が正しいのかぞうかを再 度チェックしたわけではない。なので、私の理解が不十分な箇所があるか もしれないし、完全に誤解している部分があるかもしれない。しかし、も し誤解していたとしても、その誤解も私自身の消滅定理の理解の一部分 なので、お許し下さい。

\section{1 川又-Viehweg 消滅定理について}

極小モデル理論でもつとも頻繁に用いられる定理の一つに、川又-Viehweg 消滅定理がある。学生さんが極小モデル理論を勉強しようとすると、と りあえず廣中の特異点解消定理と川又-Viehweg 消滅定理の使い方を覚え なくてはいけないのである。消滅定理も特異点解消定理も使い方を理解 することと証明を理解することは全くべつの問題なので、とにかく使い 方を覚えることが優先されるのである。専門家にはよく知られているの だが、川又と Viehwegは同時期に独立に川又-Viehweg 消滅定理を得てい る。世間一般の理解では

川又の定理とViehwegの定理は表面上は少し異なるが、本質的には 同じである。

であろう。だから、川又-Viehweg 消滅定理と呼ばれているのであろう。 たしかに、この理解は間違ってはいないと思う。川又の定理から Viehweg の定理の主張を導くことも、その逆も、それほど難しくない。したがつ て、彼らの定理の主張を研究に用いるだけという態度の人にとっては、川 又の定理もViehwegの定理も本質的に同じである。しかし、数学的内容 はどうであろうか? 私の理解では、

川又の定理と Viehwegの定理は、表面上は似ているが、本質的に異 なる定理である。

である。川又の証明は、巡回被覆をとるというトリックで、小平の消滅定 理（や乗松の消滅定理）から川又-Viehweg 消滅定理を導くのである。こ の証明の利点は、とにかく証明が簡単なうえ、手っ取り早く理解可能とい 
う点である。したがって、小平の消滅定理の主張を認めてしまうのなら、 川又によるアプローチは川又-Viehweg 消滅定理の理解の最善の方法の一 つであろう。一方、Viehwegによる川又-Viehweg 消滅定理の証明は、川 又の証明に比べると難しい。小平の消滅定理ではなく、Bogomolovの消 滅定理を使って川又-Viehweg 消滅定理を示しているのだが、Bogomolov の消滅定理自身もホッジ理論を用いて示している。Viehweg の論文は川 又の論文より若干長く難しいので、先を急ぐ大半の人は川又流の証明を 優先的に勉強してしまうのであろう。Viehwegはその後 Esnault と共同で 消滅定理についていくつかの論文を書いているのだが、彼らのアプロー チはどう見てもホッジ理論的である。Kollárによる一連の結果（Kollár のアプローチもホッジ理論的である）を理解するということも、Esnault とViehwegの目的の一つであったように思える。残念ながら、Esnault と Viehwegによる消滅定理についてのレクチャーノートは、ホッジ理論的 な記述がかなり薄められ、Deligne と Illusieによる正標数還元テクニック に重きが置かれている。このレクチャーノートがホッジ理論的な側面を 強調していれば、その後の発展は今とは少し違ったものになっていたか もしれない。さらに、Esnault と Viehwegの研究には、極小モデル理論へ の応用という視点が全くなかったように思える。極小モデル理論への応 用を念頭におき、初心に戻ってホッジ理論的な側面を重要視して消滅定 理を追究すると、ここ数年の私の一連の仕事は自然に出てくるのである。 川又による川又-Viehweg 消滅定理の証明は非常に簡単でありがたいので あるが、この方法でさらなる一般化を追究することは不可能であろう。川 又の消滅定理の偉大さは、主張自体は小平の消滅定理のちょつとした一般 化に見えるが、非常にたくさんの応用があるという点であろう。Viehweg のようなホッジ理論的なアプローチは消滅定理を使うだけの人には敬遠 されてきたように思うが、一般化を目指すにはViehwegの方を選択しな くてはいけなかったのだと思う。私の立場では、

川又の消滅定理と Viehweg の消滅定理は全く別の定理である。

である。 


\section{2 川又-Viehweg 消滅定理と Nadel 消滅定理について}

次に川又-Viehweg 消滅定理と Nadel 消滅定理の関係についての私の個 人的な考えを述べてみたい。Nadel 消滅定理は本来解析的な結果である が、ここで扱うのは代数的な設定での Nadel 消滅定理だけである。Nadel 消滅定理と乗数イデアル層の代数的な理論については、Lazarsfeld の本が 詳しい。なので、ここでは詳細については述べない。これまた世間一般では

Nadel 消滅定理と川又-Viehweg 消滅定理はほぼ同じである。

と思われている。この考えはある意味正しい。Nadel 消滅定理は明らかに 川又-Viehweg 消滅定理を含んでいる。一方、川又-Viehweg 消滅定理を 使って少し議論すると、Nadel 消滅定理を導くことができる。この点をも う少し詳しく見てみよう。登場人物は以下の 3 つの定理である。

(i) Nadel 消滅定理

(ii) 川又-Viehweg 消滅定理

(iii) (双有理射に対する) 相対的川又-Viehweg 消滅定理

Nadel 消滅定理の証明として一般的な方法は、特異点解消をとって川 又-Viehweg 消滅定理 (ii) を適用する。さらにスペクトル系列の議論と相 対的川又-Viehweg 消滅定理 (iii) を用いると、目的の Nadel 消滅定理 (i) が得られる。詳しくは Lazarsfeldの本などを見ていただきたい。相対的 な川又-Viehweg 消滅定理 (iii) は川又-Viehweg 消滅定理 (ii) とスペクトル 系列から簡単に導けることを注意しておきたい。おそらくMumford の議 論である。なので、やはり (i) と (ii) はほぼ同じである、という結論が得 られるのである。普通の人はこれで満足すると思う。さらに、大抵の人は 相対的川又-Viehweg 消滅定理 (iii) を重要視していないように思える。私 は相対的川又-Viehweg 消滅定理 (iii) は非常に大切な役割を果たす定理だ と考えている。いずれにせよ、Nadel 消滅定理 (i) と川又-Viehweg 消滅定 理 (ii) がほぼ同值であるという主張はそれなりに正しいことが分かった。 しかし、Nadel 消滅定理を川又-Viehweg 消滅定理の言い換えに過ぎない と考えていてはその後の発展が全く見えてこない。私の個人的な見解で は、(i)の Nadel 消滅定理は (少し一般化された)Kollár 消滅定理の特殊な 場合であり、(iii)の (双有理射に対する) 相対的川又-Viehweg 消滅定理は (少し一般化された)Kollárの捻れ不在定理の特殊な場合である。相対的な 
川又-Viehweg 消滅定理を Grauert-Riemenschneider 消滅定理の一般化と 見なしていてはだめだと思う。このような視点を採用すると、Kollár の 定理を一般化することで、(i) や (iii)の消滅定理のさらなる一般化が見え てくる。川又-Viehweg 消滅定理 (ii) に固執すると、一般化の方向が見え てこないのである。結論としては、

川又-Viehweg 消滅定理と Nadel 消滅定理が同じであるという見方は 捨て去るべきだ。

である。Nadel 消滅定理を (一般化された) Kollár 消滅定理の特殊な場合と 見なし、さらなる一般化を考える方が正しい方向だと思う。実際、私の 一連の仕事ではこの考え方を採用している。

\section{3 今後の課題}

川又-Viehweg 消滅定理や (代数的な設定での)Nadel 消滅定理のホッジ 理論的な側面はそれなりに理解がすすみ、十分な一般化がえられたと思 う。今後の課題の一つは、これら消滅定理の解析的側面のさらなる理解で ある。調和微分形式の理論や $L^{2}$-method を十分に発展させることは、極 小モデル理論の次の大発展のためには不可欠なステップになると思う。

\section{9 おしまい}

まだまだ書きたいことは尽きないのだが、あまり長くなると誰も読ま なくなるので、これぐらいで筆を擱きたい。論文を読むのは大変そうだ けど今回の話に興味を持ったという方には、[ふ 1]、[ふ 2]、[ふ 3]、[ふ 4] をすすめる。どれも私のホームページからダウンロード可能である。

\section{0 謝辞}

講演の機会を与えてくれたオーガナイザーの石井亮さん、高橋宣能さ ん、權業善範さんに感謝します。コメントをくれた權業善範さんと高木 俊輔さんに感謝します。最後に、私はJSPS から科学研究費補助金、若手 研究 (A)24684002 を受けています。 


\section{参考文献}

[BCHM] C. Birkar, P. Cascini, C. D. Hacon, J. M'Kernan, Existence of minimal models for varieties of log general type, J. Amer. Math. Soc. 23 (2010), no. 2, 405-468.

[ふ 1] 藤野 修、Kodaira vanishing theorem for log canonical varieties（対数的標準特異点をもった多様体に対する小平の消滅定 理) Hodge 理論、退化、特異点の代数幾何とトポロジー研究集 会（第 4 回）報告集 (2008).

[ふ 2] 藤野 修、On injectivity, vanishing, and torsion-free theorems (単射性、消滅、捻れ不在定理について) 数理解析研究所講究録, no. 1613, p6-25 (2008).

[ふ 3] 藤野 修、Vanishing theorem and non-vanishing theorem（消滅 定理と非消滅定理）数理解析研究所講究録, no. 1745, p123-138 (2011).

[ふ 4] 藤野 修、Some problems on Fano varieties（ファノ多様体につ いてのいくつかの問題) 数理解析研究所講究録, no. 1897, p4370 (2014).

[KMM] Y. Kawamata, K. Matsuda, K. Matsuki, Introduction to the minimal model problem, Algebraic geometry, Sendai, 1985, 283360, Adv. Stud. Pure Math., 10, North-Holland, Amsterdam, 1987.

[KM] J. Kollár, S. Mori, Birational geometry of algebraic varieties, Cambridge Tracts in Mathematics, 134, Cambridge University Press, Cambridge, 1998. 